\title{
Family characteristics and pedestrian injury risk in Mexican children
}

\author{
A Celis, Z Gomez, A Martinez-Sotomayor, L Arcila, M Villaseñor
}

Background: Family characteristics have been described as risk factors for child pedestrian and motor vehicle collision. Research results come mainly from developed countries, where family relationships could be different than in developing ones.

Objective: To examine family characteristics as risk factors for pedestrian injury in children living in Guadalajara City, Mexico.

Methods: Case-control study of injuries among children 1-14 years of age involved in pedestrian-motor vehicle collisions. Cases resulting in death or injuries that required hospitalization or medical attention were included and identified through police reports and/or emergency room registries. Two neighborhood matched controls were selected randomly and compared with cases to estimate odds ratios (OR) and $95 \%$ confidence intervals (CI).

See end of article for authors' affiliations Results: Significant risk factors were: male (OR $2.3,95 \% \mathrm{Cl} 1.2$ to 4.4$)$, number of siblings in household (two siblings, OR $3.2,95 \% \mathrm{Cl} 1.4$ to 6.6 ; three siblings, $\mathrm{OR} 4.5,95 \% \mathrm{Cl} 1.9$ to 11.0 ; four or more siblings, $\mathrm{OR} 3.7,95 \% \mathrm{Cl} 1.1$ to 12.9 ), and number of non-siblings/non-parents in household (four or more, OR $6.2,95 \% \mathrm{Cl} 1.5$ to 26.6). Children of a sole mother, working mother, or grandmother living in house did not show increased risk after adjusting for socioeconomic conditions.

Correspondence to: Dr Alfredo Celis, Av Naciones Unidad \#6754-9B, Virreyes Residencial, Zapopan Jalisco, Mexico; alfredo_celis@yahoo.com Conclusion: Household size has implications for child pedestrian and motor vehicle collision prevention efforts and is relatively easy to identify. Also, the lack of risk association with working mothers may indicate that grandmothers are not part of the social support network that cares for children of working mothers.

F ew studies have examined the relationship between family characteristics and child pedestrian injuries. Risk factors that have been identified include crowding, ${ }^{1-3}$ number of children at home, ${ }^{4}$ sole parenthood,,${ }^{14}$ mother's age, and being a working mother. ${ }^{3}$ For at least one risk factor, sole parenthood, an effect modification by ethnic group has been reported, ${ }^{5}$ highlighting the need for multicultural research. The present study was designed to examine the effect of family structure characteristics on child pedestrian injury in Guadalajara Metropolitan Area, Mexico, where pedestrian and motor vehicle collision is the main cause of injury death in children $1-14$ years of age. ${ }^{6}$

\section{METHODS}

A case-control study of child pedestrian injuries was conducted in the Metropolitan Area of Guadalajara (counties of Guadalajara, Zapopan, Tlaquepaque, and Tonala) during 1999. Cases were children 1-14 years old who were killed or injured and admitted to a hospital or emergency room as a result of a pedestrian-motor vehicle collision. The Attorney General Office of Jalisco and emergency care posts registries were used to identify children who met these criteria.

Two controls were chosen for each case within the same neighborhood using the following method. Upon leaving the house of each case, the interviewer knocked at the door of the house located immediately to the left asking whether a child 1-14 years old lived there; if the answer was positive, authorization was requested to conduct the interview. If more than one child lived in the house, one of them was chosen randomly as the control. If there were no children living in the house, or permission was denied to conduct the interview, the next house to the left was approached in the same manner. If no one was home, the interviewer asked neighbors whether any children 1-14 years old lived in the house. If so, three additional attempts were made to get the interview. If unsuccessful, the next house to the left was tried until the controls were obtained for the case.

Interviews for cases were conducted within the first 30 days after the injury event. Both case and control information was obtained from the parents by direct interview in the house. All characteristics investigated were pertinent to the children, the family, and the house. Child variables included gender, age in years, and time on street playing (hours/week). Family questions included home presence of parents, school education, working employment (yes, no), age, and relation to the case/control of other persons living in the house. Housing conditions included type of construction material, house type (separate house, apartment, other type), and ownership (self owned, rented, borrowed).

Relative risk for fatal and non-fatal injury was estimated using crude and adjusted odds ratios (OR). Statistical inference included 95\% confidence intervals (CI). Multivariate OR were calculated by conditional logistic regression, matching by neighborhood. Residual socioeconomic confounding was adjusted by floor material as a proxy for income. In the Metropolitan Area of Guadalajara, monthly household income for families living in a house with a floor surface made of dirt, cement, or concrete is US\$532, while for those living in a house with a floor surface made with tile or other material is US\$822 (data from the 2000 year Mexican census data base, tabulated by AC).

Abbreviations: $\mathrm{Cl}$, confidence interval; $\mathrm{OR}$, odds ratio 
Table 1 Risk of child pedestrian injury associated with sociodemographic variables

\begin{tabular}{|c|c|c|c|c|}
\hline \multirow[b]{2}{*}{ Variable } & \multicolumn{2}{|c|}{ No (\%) in group } & \multirow[b]{2}{*}{ OR } & \multirow[b]{2}{*}{$95 \% \mathrm{Cl}$} \\
\hline & Cases & Controls & & \\
\hline \multicolumn{5}{|l|}{ Floor material } \\
\hline Dirt, cement, or concrete & $18(20.9)$ & $21(12.2)$ & 1.9 & 0.9 to 4.0 \\
\hline Tile or other & 68 (79.1) & $151(87.8)$ & 1.0 & \\
\hline \multicolumn{5}{|l|}{ Housing type } \\
\hline Separated house & 73 (84.9) & $151(87.8)$ & 1.0 & \\
\hline Apartment & $8(9.3)$ & $12(7.0)$ & 1.4 & 0.5 to 3.8 \\
\hline Other type of housing & $5(5.8)$ & $9(5.2)$ & 1.1 & 0.3 to 4.0 \\
\hline \multicolumn{5}{|l|}{ House ownership } \\
\hline Self owned & 51 (59.3) & $100(58.1)$ & 1.0 & \\
\hline Rented & $22(25.6)$ & $57(33.1)$ & 0.8 & 0.4 to 1.4 \\
\hline Borrowed & $13(15.1)$ & $15(8.7)$ & 1.7 & 0.7 to 4.2 \\
\hline \multicolumn{5}{|l|}{ Father's age (years) * } \\
\hline $17-24$ & $3(4.3)$ & $6(4.3)$ & 0.8 & 0.1 to 4.1 \\
\hline $25-34$ & 22 (31.9) & $60(43.5)$ & 0.6 & 0.3 to 1.2 \\
\hline$\geqslant 35$ & $44(63.8)$ & 72 (52.2) & 1.0 & \\
\hline \multicolumn{5}{|l|}{ Father's education (years of school)* } \\
\hline Elementary or less ( $\leqslant 6$ years) & $41(59.4)$ & $86(62.3)$ & 0.9 & 0.5 to 1.7 \\
\hline More than elementary (>6 years) & $28(40.6)$ & 52 (37.7) & 1.0 & \\
\hline \multicolumn{5}{|l|}{ Working father* } \\
\hline No & $4(5.8)$ & $6(4.3)$ & 1.4 & 0.3 to 5.9 \\
\hline Yes & $65(94.2)$ & $132(95.7)$ & 1.0 & \\
\hline \multicolumn{5}{|l|}{ Mother's age (years) $\dagger$} \\
\hline $17-24$ & $5(6.0)$ & 20 (11.7) & 0.4 & 0.1 to 1.2 \\
\hline $25-34$ & $36(42.9)$ & $83(48.5)$ & 0.7 & 0.4 to 1.2 \\
\hline$\geqslant 35$ & $43(51.2)$ & $68(39.8)$ & 1.0 & \\
\hline \multicolumn{5}{|l|}{ Working mothert } \\
\hline No & $59(70.2)$ & $142(83.0)$ & 1.0 & \\
\hline Yes & $25(29.8)$ & $29(17.0)$ & 2.1 & 1.1 to 4.0 \\
\hline \multicolumn{5}{|l|}{ Mother's education (years of school) $\dagger$} \\
\hline Elementary or less ( $\leqslant 6$ years) & $47(56.0)$ & $101(59.1)$ & 0.9 & 0.5 to 1.6 \\
\hline More than elementary ( $>6$ years) & $37(44.0)$ & $70(40.9)$ & 1.0 & \\
\hline
\end{tabular}

Table 2 Risk of child pedestrian injury associated with child variables

\begin{tabular}{lllll}
\hline & \multicolumn{2}{l}{ No $(\%)$ in group } & & \\
\cline { 2 - 3 } Variable & Cases & Controls & OR & $95 \% \mathrm{Cl}$ \\
\hline $\begin{array}{l}\text { Gender } \\
\text { Female }\end{array}$ & $30(34.9)$ & $80(46.5)$ & 1.0 & \\
$\begin{array}{l}\text { Male } \\
\text { Age group (years) }\end{array}$ & $56(65.1)$ & $92(53.5)$ & 1.6 & 0.4 to 1.1 \\
$1-4$ & $24(27.9)$ & $44(25.6)$ & 1.4 & 0.7 to 3.0 \\
$5-9$ & $38(44.2)$ & $65(37.8)$ & 1.5 & 0.8 to 3.0 \\
$10-14$ & $24(27.9)$ & $63(36.6)$ & 1.0 & \\
Time on street playing (hours/week) & $37(43.0)$ & $96(55.8)$ & 1.0 & \\
0 & $23(26.7)$ & $41(23.8)$ & 1.5 & 0.7 to 2.9 \\
$1-5$ & $13(15.1)$ & $21(12.2)$ & 1.6 & 0.7 to 3.8 \\
$6-10$ & $13(15.1)$ & $14(8.1)$ & 2.4 & 0.9 to 6.1 \\
$\geqslant 11$ & & & &
\end{tabular}

\section{RESULTS}

A total of 131 fatal and non-fatal child pedestrian injuries were identified during the study period. Interviews were conducted with 86 of the eligible cases $(66 \%)$; missing cases included 31 false addresses $(23.7 \%)$, nine refused to participate $(6.9 \%)$, four moved out $(3.0 \%)$, and one was not found after three visits $(0.8 \%)$. Neighborhoods did not differ between missing and completed cases. Among potential controls, 11 refused to participate $(6.4 \%)$, and they were substituted by neighbors.

Despite matching by neighborhood, socioeconomic differences existed between cases and controls (table 1). Cases were more likely to live in houses with dirt, cement or concrete floors, in apartments, and borrowed places. Cases also more frequently had a mother working (OR $2.1,95 \%$ CI 1.1 to 4.0 ).
Parent age and education and father working did not show significant differences.

Regarding child characteristics (table 2), cases were more likely males (OR 1.6; $95 \%$ CI 0.4 to 1.1 ), younger than 10 years old (OR $1-4$ years old $1.4,95 \%$ CI 0.7 to $3.0 ; 5-9$ years old 1.5 , $95 \%$ CI 0.8 to 3.0 ), and spent more time on the street playing (trend $\chi^{2}, \mathrm{p}<0.05$ ).

Table 3 shows the risk associated with persons living in the house. Sole motherhood was not associated with increased risk. However, the risk for pedestrian injury increased as the number of siblings increased (trend $\chi^{2}, \mathrm{p}<0.05$ ). Likewise, the risk for children living in houses shared with five or more non-siblings/non-parents is higher (OR 2.0, 95\% CI 0.7 to 5.9 ) than those living in houses shared with four or fewer non-siblings/non-parents. Some of these non-siblings/nonparents include the grandmother and the grandfather, which 
Table 3 Risk of child pedestrian injury associated with persons living in the house

\begin{tabular}{|c|c|c|c|c|}
\hline \multirow[b]{2}{*}{ Variable } & \multicolumn{2}{|c|}{ No (\%) in group } & \multirow[b]{2}{*}{ OR } & \multirow[b]{2}{*}{$95 \% \mathrm{Cl}$} \\
\hline & Cases & Controls & & \\
\hline \multicolumn{5}{|c|}{ Parents in the house } \\
\hline Both parents & $68(79.1)$ & $138(80.2)$ & 1.0 & \\
\hline Sole father & $1(1.2)$ & 0 & & \\
\hline Sole mother & $16(18.6)$ & 33 (19.2) & 1.0 & 0.5 to 2.0 \\
\hline None & $1(1.2)$ & $1(0.6)$ & 2.0 & \\
\hline \multicolumn{5}{|c|}{ Number of siblings in the house } \\
\hline 0 or 1 & $28(32.6)$ & $92(53.5)$ & 1.0 & \\
\hline 2 & $27(31.4)$ & $42(24.4)$ & 2.1 & 1.5 to 4.2 \\
\hline 3 & $22(25.6)$ & $23(13.4)$ & 3.1 & 1.4 to 6.9 \\
\hline$\geqslant 4$ & $9(10.5)$ & $15(8.7)$ & 2.0 & 0.7 to 5.4 \\
\hline \multicolumn{5}{|c|}{ Number of non-siblings/non-parents in the house } \\
\hline 0 & $70(81.4)$ & $138(80.2)$ & 1.0 & \\
\hline $1-4$ & $7(8.1)$ & $25(14.5)$ & 0.6 & 0.2 to 1.4 \\
\hline$\geqslant 5$ & 9 (10.5) & $9(5.2)$ & 2.0 & 0.7 to 5.9 \\
\hline \multicolumn{5}{|c|}{ Grandmother in the house } \\
\hline No & 73 (84.9) & $157(45.6)$ & 1.0 & \\
\hline Yes & $13(15.1)$ & $15(4.4)$ & 1.9 & 0.8 to 4.4 \\
\hline \multicolumn{5}{|c|}{ Grandfather in the house } \\
\hline No & 78 (90.7) & 160 (31.0) & 1.0 & \\
\hline Yes & $8(9.3)$ & $12(2.3)$ & 1.4 & 0.5 to 3.8 \\
\hline
\end{tabular}

Table 4 Adjusted odd ratios and $95 \%$ confidence intervals for selected variables

\begin{tabular}{lcc}
\hline Variable & OR (adjusted) & $95 \% \mathrm{Cl}$ \\
\hline Sex & 1.0 & \\
Female & 2.3 & 1.2 to 4.4 \\
Male & \\
Number of siblings in the house & \\
0 or 1 & 1.0 & 1.4 to 6.6 \\
2 & 3.1 & 1.9 to 11.0 \\
3 & 4.6 & 1.1 to 12.9 \\
$\geqslant 4$ & 3.7 & \\
Number of non-siblings/non-parents in the house & \\
$\leqslant 3$ & 1.0 & 1.5 to 26.6 \\
$\geqslant 4$ & 6.2 & \\
\hline \multirow{2}{*}{ *Estimators adjusted reciprocally by floor material and time of } \\
on-street playing.
\end{tabular}

showed a weak association with child pedestrian injury (OR $1.9,95 \%$ CI 0.8 to 4.4 ; OR $1.4,95 \%$ CI 0.5 to 3.8 ; respectively).

Multivariate analyses were conducted adjusting by floor material (a proxy of socioeconomic condition) and time playing on the street (table 4). Statistically significant associations are found for male gender (OR 2.3, 95\% CI 1.2 to 4.4 ), number of siblings in the house (two siblings, OR $3.1,95 \%$ CI 1.4 to 6.6; three siblings, OR 4.6, 95\% CI 1.9 to 11.0 ; four or more siblings, OR $3.7,95 \%$ CI 1.1 to 12.9 ), and four or more non-siblings/ non-parents living in the house (OR $6.2,95 \%$ CI 1.5 to 26.6 ). At this time we were interested in looking at non-siblings/ non-parents who were aged 15 or over. When four or more are taken into account, the adjusted OR is $6.7,95 \%$ CI 1.5 to 29.2 (result not show in table). No association with sole motherhood or grandmother living in the same house was found.

\section{DISCUSSION}

Results from this study confirm previous reports that associate crowding in a house with an increase risk of pedestrian and motor vehicle collision for children 1-14 years old. This association is independent from socioeconomic condition and time playing on the street. This could be explained by two different causal mechanisms: one related to the number of siblings and another with the number of non-siblings/nonparents living in the same house. Morrongiello and Bradley explored the influence of older siblings on younger siblings, highlighting the potential power to influence them in certain behaviors. ${ }^{7}$ It would seem believable in a household with a greater number of siblings that one of them would undertake greater risk behaviors with certain frequency. This child would influence the decision making process of his brothers or sisters. This might explain why there is a relationship between the number of brothers/sisters and injury in pedestrian and motor vehicle collisions. On the other hand, we do not know of any association already reported between number of nonsiblings/non-parents living in the same house and the risk of pedestrian injury. Agran et al explored the relationship that might exist between no, one, and two or more related adults living in the same house and risk of injury, finding a very slight association, statistically non-significant. ${ }^{1}$ We also found increased risk with four or more non-siblings/non-parents living in the same house; however some of them were not related to the cases. Additionally, this association persisted when only those 15 or more years of age were taken into account. One potential explanation for this is that with so many people living in the same house, the responsibility for care of children falls on several of them, but nobody in particular complies.

In contrast to other studies we did not find a greater risk for children living only with one parent. ${ }^{145}$ Roberts reported that this association was modified by ethnic group, remarking that the risk was different depending upon the origin of the family: European, Maori, or Pacific Islander. ${ }^{5}$ Later, Roberts and Pless pointed out that the association between "lone parenthood and childhood injury could be explained in terms of ... poverty, poor housing, and social isolation", which are frequent characteristics of lone mothers. ${ }^{8}$ Our study supports this conclusion as case-control matching by neighborhood eliminated confounding by socioeconomic factors.

Crude analysis showed an increased risk for children whose mothers had to work outside the home, but this risk did not hold after adjusting by material of the floors (proxy of household income) and by time playing on the street. This result differs from that reported by others. ${ }^{3}$ We also assumed that if there was a support network for child care, the grandmother could be part of it. However, the crude analysis showed the grandmother increased the risk of injury by $90 \%$. This makes sense if a grandmother's age and health affect the level of attention and care required by a child less than 15 years old.

A strength of this study was the willingness of subjects to be interviewed. The majority of cases and controls participated 


\section{Key points}

- Household size is a key risk factor.

- Crowding as a risk factor could be explained by at least two different etiologic paths: one related to the number of siblings living in the house and the other with the number of non-siblings/non-parents living at home.

- In the Guadalajara Metropolitan Area, sole motherhood and being a working mother are not risk factors.

- Presence of a grandmother living in the house does not change risk.

(refusal rates below 7\%). Study limitations include the inability to locate all potential cases, primarily because of false addresses $(23.7 \%)$. Another study in this region reported similar problems with false addresses $(20.0 \%) .{ }^{9}$ However, we have no evidence to support any association between false addresses and studied risk factors. If there is a bias, we believe it would be non-differential.

A second limitation is the questionnaire. While it was structured with short questions and closed answers, it was not validated. Since the same questionnaire was used for both cases and controls, bias would likely be towards the null. Memory bias is also a concern for case-control studies. Since interviews were conducted within one month after the event, and almost all explored risk factors have a very low change rate, memory would have little impact. Of major concern, however, is the time on-street playing. Since this variable was used only to adjust for odds ratios in the multivariate analysis, we do not know if this introduced a differential bias between cases and controls.

\section{IMPLICATIONS FOR PREVENTION}

Although family size is not likely to be a modifiable risk factor, it could be used to identify children at greater risk for injuries as pedestrians and direct preventive measures such as home visits. ${ }^{10}$ It is clear that increased numbers of household members put children at risk of pedestrian injuries, and this association is independent of socioeconomic condition and time playing on the street. Because it seems that closer supervision for children with high numbers of household members decreases rather than increases, preventive actions to reduced risk must be supported by environmental rather than educational interventions. Finally, identifying whether large households contain family or non-family members is necessary when developing strategies to reduce child pedestrian and motor vehicle collision.

\section{Authors' affiliations}

A Celis, Z Gomez, A Martinez-Sotomayor, L Arcila, M Villaseñor, University of Guadalajara, Mexican Institute of Social Security

\section{REFERENCES}

1 Agran PF, Winn DG, Anderson CL, et al. Family, social, and cultural factors in pedestrian injuries among Hispanic children. Inj Prev 1998:4:188-93.

2 Christoffel KK, Donovan M, Schofer J, et al. Psychosocial factors in childhood pedestrian injury: a matched case-control study. Pediatrics 1996;97:33-42.

3 Wazana A, Krueger $P$, Raina $P$, et al. A review of risk factors for child pedestrian injuries: are they modifiable? Inj Prev 1997:3:295-304.

4 Roberts I, Norton R. Sensory deficit and the risk of pedestrian injury. $\ln j$ Prev 1995; 1:12-14.

5 Roberts I. Sole parenthood and the risk of child pedestrian injury. J Paediatr Child Health 1994;30:530-2.

6 Celis A, Valencia N. Traumatismos y envenenamientos en Jalisco. Un estudio de la mortalidad a partir de autopsias. Salud Publica Mex 1991;33:77-87.

7 Morrongiello BA, Bradley MDM. Sibling power: influence of older siblings' persuasive appeals on younger siblings' judgments about risk siblings persuasive appeals on younger
taking behaviors. Inj Prev 1997;3:23-8.

taking behaviors. Inj Prev 1997;3:23-8.
8 Roberts I, Pless B. Social policy as a cause of childhood accidents: the children of lone mothers. BM 1995;311:925-8.

9 Celis A. Home drowning among preschool age Mexican children. Inj Prev 1997;3:252-6.

10 Roberts I, Kramer MS, Suissa S. Does home visiting prevent childhood injury? A systematic review of randomized controlled trials. $B M$ $1996 ; 312: 29-33$ 